\title{
Snow resisting capacity of Caragana microphylla and Achnatherum splendens in a typical steppe region of Inner Mongolia, China
}

\author{
YAN Min ${ }^{1}$, ZUO Hejun ${ }^{1 *}$, WANG Haibing ${ }^{1}$, DONG Zhi' ${ }^{2}$, LI Gangtie ${ }^{1}$ \\ ${ }^{1}$ Key Laboratory of Aeolian Physics and Desertification Control Engineering, Inner Mongolia Autonomous Region, \\ College of Desert Control Science and Engineering, Inner Mongolia Agricultural University, Hohhot 010018, China; \\ ${ }^{2}$ Forestry College, Shandong Agricultural University, Tai'an 271018, China
}

\begin{abstract}
Snow resisting capacity of vegetation is important for secondary distribution of water resources in seasonal snow areas of grassland because it affects the regeneration, growth and nutrient circulation of vegetation in grassland. This study investigated vegetation characteristics (canopy height, canopy length and crown width) of Caragana microphylla Lam. (shrub) and Achnatherum splendens (Trin.) Nevski. (herb), and snow morphologies (snow depth, snow width and snow braid length) in a typical steppe region of Inner Mongolia, China in 2017. And the influence of vegetation characteristic on snow resisting capacity (the indices of bottom area of snow and snow volume reflect snow resisting capacity) was analyzed. The results showed that snow morphology depends on vegetation characteristics of shrub and herb. The canopy height was found to have the greatest influence on snow depth and the crown width had the greatest influence on snow width. The canopy length was found to have little influence on morphological parameters of snow. When the windward areas of C. microphylla and A. splendens were within the ranges of $0.0-0.5 \mathrm{~m}^{2}$ and $0.0-8.0 \mathrm{~m}^{2}$, respectively, the variation of snow cover was large; however, beyond these areas, the variation of snow cover became gradually stable. The potential area of snow retardation for a single plant was $1.5-2.5 \mathrm{~m}^{2}$ and the amount of snow resistance was $0.15-0.20 \mathrm{~m}^{3}$. The bottom area of snow and snow volume (i.e., snow resisting capacity) of clumped $C$. microphylla and $A$. splendens was found to be 4 and 25 times that of individual plant, respectively. The results could provide a theoretical basis both for the estimation of snow cover and the establishment of a plant-based technical system for the control of windblown snow in the typical steppe region of Inner Mongolia.
\end{abstract}

Keywords: herb; shrub; snow cover; snow resisting capacity; field observation; steppe

Citation: YAN Min, ZUO Hejun, WANG Haibing, DONG Zhi, LI Gangtie. 2020. Snow resisting capacity of Caragana microphylla and Achnatherum splendens in a typical steppe region of Inner Mongolia, China. Journal of Arid Land, 12(2): 294-302. https://doi.org/10.1007/s40333-019-0021-x

\section{Introduction}

Seasonal snow cover is an important fresh water resource in grassland (Conner et al., 2017). The effects of wind protection, snow blocking and snow retention by vegetation can cause drifting to form secondary accumulation of snow on the leeward side of shrubs and herbs, such that the snow cover could be redistributed within a certain space (Leonard and Maksym, 2011). Topography, wind force, snow source and shrub-herb characteristics can affect the range of disturbance,

\footnotetext{
*Corresponding author: ZUO Hejun (E-mail: zuohj@126.com)

Received 2018-11-21; revised 2019-03-08; accepted 2019-07-03

(C) Xinjiang Institute of Ecology and Geography, Chinese Academy of Sciences, Science Press and Springer-Verlag GmbH Germany, part of Springer Nature 2020
} 
potential range of snow cover and snow resisting capacity (Sturm et al., 2001; Essery and Pomeroy, 2004; Pomeroy et al., 2006). The amount of snow accumulation determines the time of reviving of herb vegetation in the following year, ground temperature, speed of vegetation growth and development and biomass (Fan et al., 2013; Tommaso et al., 2014). Moreover, the formation of snow in association with shrubs and herbs is important for plant species composition, vegetation structure, soil carbon storage, surface water geochemistry, decomposition, invertebrate and vertebrate populations and the spectral reflection of vegetation (Walker et al., 1995; Marion et al., 1997; Johansson et al., 2013; Gavazov et al., 2017).

The relationship between snow morphology and vegetation characteristics in steppe regions is complex (Myers-Smith, 2011; Naito and Cairns, 2011). The hydrological processes (e.g., snow cover, distribution and ablation) of grassland areas are considerably affected by vegetation characteristics (Marsh et al., 2010; Liston and Hiemstra, 2011). On the contrary, snow cover can affect the physiological and ecological processes of vegetation in steppe regions, e.g., snow cover is known to have significant correlation with vegetation growth in the succeeding year (Jones et al., 2001; Hallinger et al., 2010; Schmidt et al., 2010; Wipf and Rixen, 2010; Cacitua et al., 2013). Based on field observation and numerical simulation, researchers have preliminarily found the status and the function of snow cover affecting by vegetation. For example, using the CLM4 (community land model 4) and CAM4 (community atmosphere model 4) models, Lawrence et al. (2011) found that a $20 \%$ increase in vegetation density could lead to a corresponding $40 \mathrm{~cm}$ increase in snow depth. Field observations indicated that the process of snow accumulation is controlled by blocking of wind and blowing snow. For example, Dolman et al. (2001) found that snow depth in areas of tundra shrub is about $27 \%$ higher than in areas of herb, and that a slight increase in shrub canopy height could cause a remarkable increase in snow depth. Pomeroy et al. (1997) found that snow depth in areas of arctic shrub was 4-5 times that of areas of sparse vegetation. Sturm et al. (2005) also found that vegetation height significantly affected snow depth, and that snow depth in areas of shrub was higher than in areas of no vegetation. And individual patches of shrub and the edges of larger areas of vegetation can serve as a depository for windblown snow by intercepting large amounts of snow blown from the tundra. The snow resisting capacity of vegetation is of great importance for the control of snow-related damage in steppe regions in winter.

Current research into vegetation and snow cover in steppe regions is primarily focused on large-scale remote sensing monitoring, e.g., snow cover and vegetation parameters can be extracted from AVHRR and MODIS data. Thus, the relationships of snow cover and climate, vegetation and topography can be established within the context of large- and medium-scale remote sensing technology. However, the inversion accuracy is considerably affected by vegetation, especially shrub, and it has been confirmed that shrub is the biggest source of uncertainty in the extraction of snow-related parameters (Cornelissen and Makoto, 2014; Tinkham et al., 2014). Moreover, snow resisting capacity of shrubs and herbs has not been studied in depth. In this study, we used bottom area of snow and snow volume to reflect the snow resisting capacity of shrubs and herbs.

The temperate steppe region in Inner Mongolia represents an important part of the world largest grassland biome in the Eurasian continent, covering a total area of $8.86 \times 10^{7} \mathrm{hm}^{2}$. Caragana microphylla Lam. and Achnatherum splendens (Trin.) Nevski. are typical shrubs and herbs in the steppe region due to their drought, cold and saline resistance traits. Therefore, these two types of typical vegetation were used to study the influence of vegetation characteristics on the formation of snow, range and amount of snow retention and to analyze the snow resisting capacity. The aim of this study was to provide a theoretical basis both for the estimation of snow cover and the establishment of a plant-based technical system for the control of windblown snow in the typical steppe region.

\section{Study area and methods}

\subsection{Study area}

Xilin Gol League $\left(44^{\circ} 16^{\prime} 08^{\prime \prime}-44^{\circ} 25^{\prime} 25^{\prime \prime} \mathrm{N}, 116^{\circ} 14^{\prime} 25^{\prime \prime}-116^{\circ} 29^{\prime} 09^{\prime \prime} \mathrm{E}\right)$ is a typical steppe region 
located in the middle of Inner Mongolia Autonomous Region, China. The area receives seasonal snow cover (in winter and spring) with a long-term snow days $(100 \mathrm{~d})$. The average annual precipitation is $286.4 \mathrm{~mm}$, average annual snowfall is $23.2 \mathrm{~mm}$, and average annual snow depth is $1-5 \mathrm{~cm}$. The annual average temperature is $1.7^{\circ} \mathrm{C}$ and the frost-free period is $90-115 \mathrm{~d}$. The annual average wind speed is $4.5 \mathrm{~m} / \mathrm{s}$, annual number of gale days is $10-15 \mathrm{~d}$ and the prevailing wind is northwesterly. Xilin Gol League has suffered frequent natural disasters. For example, in the past 50 years, this area has experienced 19 droughts and 22 snowstorms, including three major snowstorms that occurred in 1962, 1977 and 2000 (Hao et al., 2006).

Figure 1 shows the distribution of shrubs and herbs in the typical steppe region of Xilin Gol League, Inner Mongolia, China. A. splendens is a typical herb species and C. microphylla is a shrub that is widely distributed across the steppe. In addition, the snow morphology in the region is associated with these two types of vegetation. Therefore, we selected $A$. splendens and $C$. microphylla as study materials. The terrain of the study area is reasonably flat that largely eliminates any influence of microtopography on wind disturbance and the development of snow morphology around the vegetation. Thus, the main influences on snow morphology associated with the shrubs and herbs in this study were the physical characteristics of the vegetation.

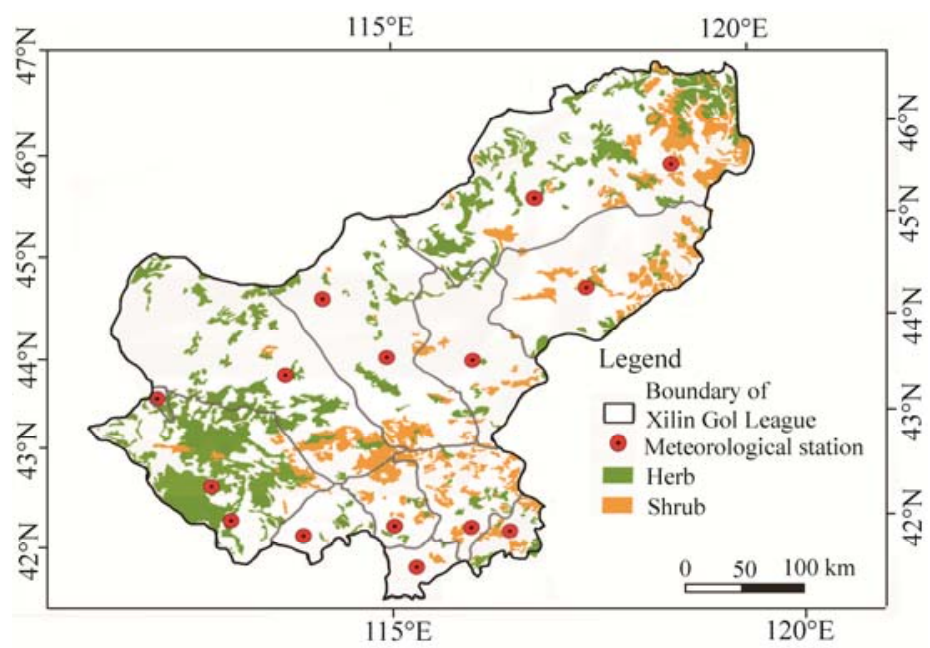

Fig. 1 Distribution of shrub (Caragana microphylla) and herb (Achnatherum splendens) in Xilin Gol League, Inner Mongolia, China

\subsection{Methods}

\subsubsection{Field survey}

Snowfall is abundant within the study area during December-January due to the frequent occurrence of strong wind and long periods of low temperature. January is the coldest month of the entire year (Fig. 2) and is the period with the largest amount of snow. Thus, in this study, field observations were conducted on 10-29 January 2017.

Overall, 60 specimens of C. microphylla (30 samples) and A. splendens (30 samples) were selected from five plots $(5 \mathrm{~m} \times 5 \mathrm{~m})$. In addition, three $10 \mathrm{~m} \times 10 \mathrm{~m}$ plots were selected in these samples of each species for identifying the grouped vegetation type (Fig. 3). C. microphylla is the dominant shrub species and $A$. splendens is the only associated species in the study area, thus the grouped vegetation type is defined by the distributional characteristic of $A$. splendens. Four grouped vegetation types were identified: type A (two A. splendens plants side by side) (Fig. $3 \mathrm{~d}$ ), type $\mathrm{B}$ (three plants $A$. splendens side by side) (Fig. 3g), type C (one A. splendens is in former and two $A$. splendens plants at the back) (Fig. 3e) and type D (the crumby and loose distribution of $A$. splendens) (Fig. 3h). This investigation included the determination of vegetation characteristics, i.e., shrub and herb height (Hp), crown width (Wp) and canopy length $(\mathrm{P})$ and snow morphologies, i.e., snow depth (H), snow width (W) and snow braid length (L) (Fig. 3f). Measurement sets of L ( $x$-axis), $\mathrm{W}$ ( $y$-axis), and $\mathrm{H}$ (z-axis) were acquired at 10 -cm intervals in both $x$ and $y$ directions 
using a steel rule. Then, statistical methods were used for spatial interpolation of the measured coordinates of each point $(X, Y$ and $Z$ ) to calculate the bottom area of snow and snow volume by Surfer 11.0 software (Golden Software, USA).

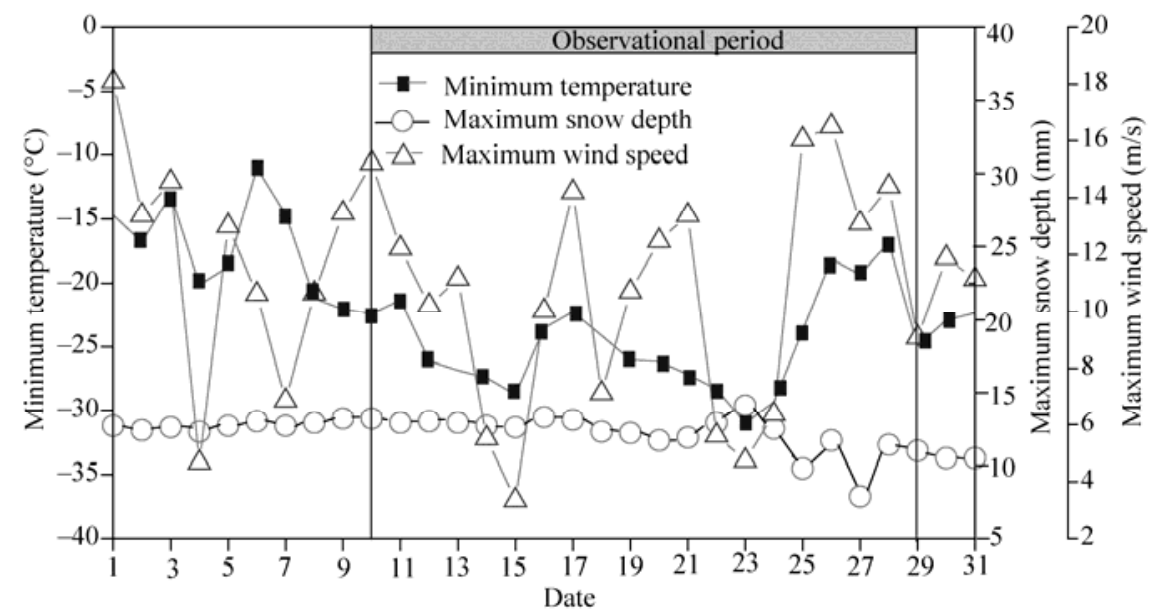

Fig. 2 Meteorological data on 1-31 January 2017 and observational period of the study

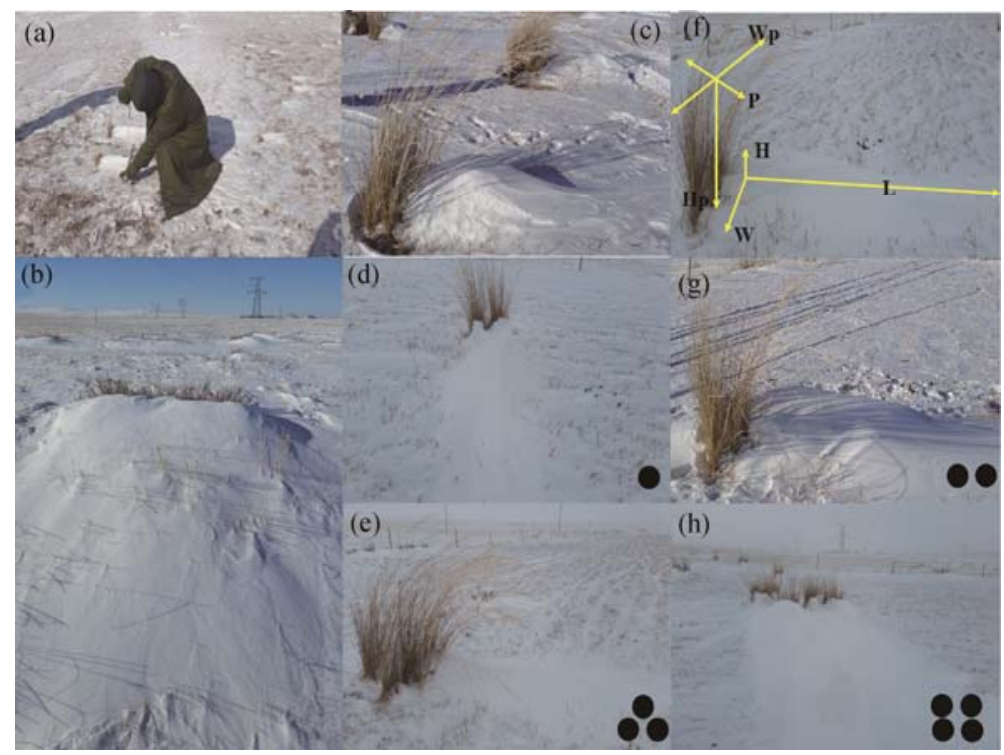

Fig. 3 Examples of the experimental conditions. (a) and (f) show the field observations of snow morphology and characteristics of shrub and herb; (b) and (c) show the snow morphology of a single plant (b, Caragana microphylla; c, Achnatherum splendens); (d) two A. splendens plants side by side (type A); (g) three A. splendens plants side by side (type B), (e) one A. splendens is in former and two A. splendens plants at the back (type C); and (h) crumby and loose distribution of $A$. splendens (type D). Hp, canopy height; Wp, crown width; $\mathrm{P}$, canopy length; H, snow depth; W, snow width; L, snow braid length.

\subsubsection{Data analysis}

Correlation analyses of all morphological parameters (one-power factors) and multiplication between parameters (quadratic factors and cube factors) with bottom area of snow and snow volume were conducted. The factors that significantly affected snow resisting capacity were analyzed. Six factors were selected in relation to bottom area of snow: $\mathrm{Hp}^{2}, \mathrm{Wp}^{2}, \mathrm{P}^{2}, \mathrm{Hp} \times \mathrm{Wp}$, $\mathrm{Hp} \times \mathrm{P}$, and $\mathrm{Wp}$ and 10 factors were selected in relation to snow volume: $\mathrm{Hp}^{3}, \mathrm{Wp}^{3}, \mathrm{P}^{3}, \mathrm{Hp} \times \mathrm{Wp}^{2}$, $\mathrm{Hp} \times \mathrm{P}^{2}, \mathrm{Hp}^{2} \times \mathrm{Wp}, \mathrm{Hp}^{2} \times \mathrm{P}, \mathrm{Wp} \times \mathrm{P}^{2}, \mathrm{Wp} \times \mathrm{P}^{2}, \mathrm{Wp}^{2} \times \mathrm{P}, \mathrm{Wp}^{2} \times \mathrm{P}, \mathrm{Wp}^{2} \times \mathrm{P}$, and $\mathrm{Hp} \times \mathrm{Wp} \times \mathrm{P}$. Finally, selected factors were used to establish the relationships between bottom area of snow and snow 
volume, and a significance test was used to determine snow resisting capacity of different snow morphologies.

\section{Results}

\subsection{Relationships between shrub and herb characteristics and snow morphologies}

Figure 4 showed the relationships between characteristics of C. microphylla and A. splendens and snow morphological parameters. It can be seen that snow depth, snow width, and snow braid length associated with the canopy height, crown width and canopy length of the species, and the linear relationship was significant $\left(R^{2}>0.50\right)$. Among various parameters, the height of $C$. microphylla had the greatest influence on snow depth $\left(R^{2}=0.75\right)$, whereas crown width $\left(R^{2}=0.91\right)$ and canopy length $\left(R^{2}=0.76\right)$ had the most significant effects on snow width. The canopy height, crown width and canopy length of $A$. splendens all had strong correlation with snow braid length with $R^{2}$ values of $0.92,0.85$ and 0.69 , respectively. Among all morphological parameters, the relationship between canopy height and snow depth was the most significant in A. splendens, while in $C$. microphylla, it was the relationship between crown width and snow width. In terms of the same characteristics of shrubs and herbs, the canopy height and crown width $\left(R_{\text {mean }}^{2}=0.75\right)$ were the main factors that determine snow morphology, while canopy length had less influence $\left(R_{\text {mean }}^{2}=0.63\right)$.
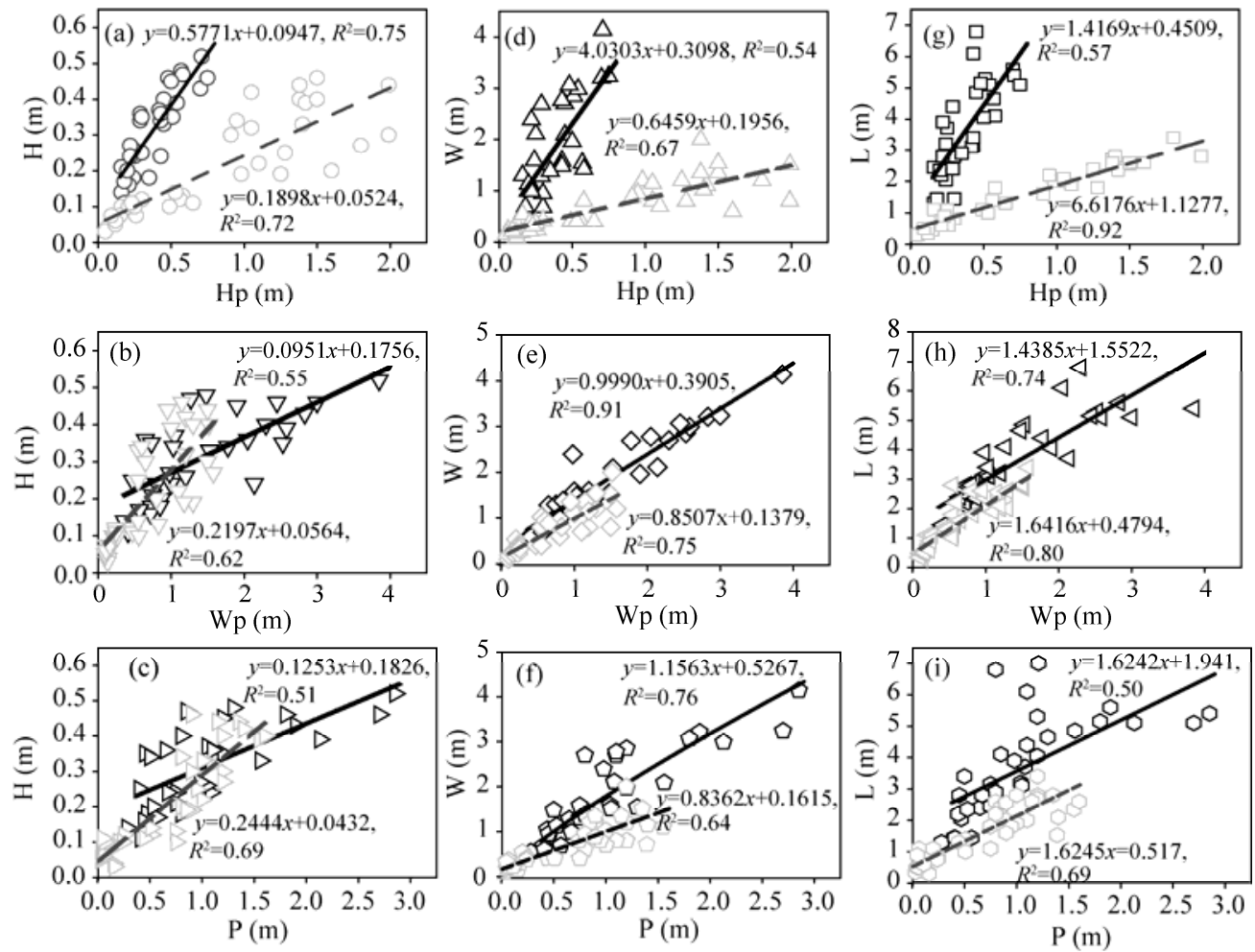

Fig. 4 Relationships of snow morphologies with the characteristics of shrub (Caragana microphylla, black and solid line) and herb (Achnatherum splendens, grey and dashed line). Hp, canopy height; Wp, crown width; P, canopy length; H, snow depth; W, snow width; L, snow braid length.

\subsection{Snow characteristics of individual and grouped herbs}

Table 1 presented the results of vegetation characteristics and snow morphologies of individual and grouped $A$. splendens. It can be seen that the snow morphologies of different grouped $A$. splendens differed significantly. The bottom area of snow and snow volume of grouped $A$. splendens increased exponentially with the increases in vegetation height and crown width. For example, the bottom area of snow and snow volume in type A was about 2 and 4 times those of 
individual plant (mean value of small, medium and large plants), respectively. In type B, they are respectively 4 and 20 times. In type C, they are respectively 3 and 8 times and in type $\mathrm{D}$, they are respectively 4 and 25 times. The maximum bottom area of snow occurred in type A, while the maximum snow volume occurred in type $\mathrm{D}$.

Table 1 Snow morphologies in different individual and grouped vegetation types

\begin{tabular}{cccccccccc}
\hline $\begin{array}{c}\text { Vegetation } \\
\text { type }\end{array}$ & $\mathrm{Hp}(\mathrm{m})$ & $\mathrm{Wp}(\mathrm{m})$ & $\mathrm{P}(\mathrm{m})$ & $\mathrm{H}(\mathrm{m})$ & $\mathrm{W}(\mathrm{m})$ & $\mathrm{L}(\mathrm{m})$ & $\mathrm{Sp}\left(\mathrm{m}^{2}\right)$ & $\mathrm{S}\left(\mathrm{m}^{2}\right)$ & $\mathrm{V}\left(\mathrm{m}^{3}\right)$ \\
\hline $\begin{array}{c}\text { Single plant } \\
\text { (Small) }\end{array}$ & $0.19 \pm 0.11$ & $0.20 \pm 0.10$ & $0.14 \pm 0.12$ & $0.08 \pm 0.03$ & $0.27 \pm 0.10$ & $0.66 \pm 0.28$ & $0.28 \pm 0.11$ & $0.32 \pm 0.18$ & $0.02 \pm 0.01$ \\
$\begin{array}{c}\text { Single plant } \\
\text { (Medium) }\end{array}$ & $0.90 \pm 0.27$ & $0.72 \pm 0.21$ & $0.80 \pm 0.16$ & $0.20 \pm 0.07$ & $0.73 \pm 0.20$ & $1.80 \pm 0.38$ & $0.56 \pm 0.20$ & $1.27 \pm 0.52$ & $0.07 \pm 0.03$ \\
$\begin{array}{c}\text { Single plant } \\
\text { (Large) }\end{array}$ & $1.60 \pm 0.24$ & $1.34 \pm 0.17$ & $1.27 \pm 0.19$ & $0.39 \pm 0.05$ & $1.36 \pm 0.27$ & $2.73 \pm 0.27$ & $1.70 \pm 0.84$ & $1.85 \pm 0.36$ & $0.16 \pm 0.02$ \\
$\quad$ Type A & $1.59 \pm 0.29$ & $2.13 \pm 0.78$ & $1.68 \pm 0.35$ & $0.46 \pm 0.20$ & $2.31 \pm 0.76$ & $6.78 \pm 2.85$ & $3.77 \pm 2.03$ & $3.15 \pm 0.38$ & $1.00 \pm 0.45$ \\
Type B & $1.68 \pm 0.05$ & $3.82 \pm 0.94$ & $1.83 \pm 0.65$ & $0.44 \pm 0.15$ & $4.03 \pm 0.20$ & $8.47 \pm 0.81$ & $7.37 \pm 4.36$ & $8.13 \pm 1.21$ & $3.32 \pm 0.08$ \\
$\quad$ Type C & $1.53 \pm 0.58$ & $2.27 \pm 0.38$ & $2.18 \pm 0.35$ & $0.43 \pm 0.08$ & $2.28 \pm 0.03$ & $6.72 \pm 0.73$ & $4.98 \pm 1.26$ & $6.23 \pm 0.94$ & $1.33 \pm 0.22$ \\
Type D & $1.52 \pm 0.48$ & $3.25 \pm 1.28$ & $2.95 \pm 0.74$ & $0.65 \pm 0.22$ & $3.15 \pm 0.82$ & $7.95 \pm 1.92$ & $9.86 \pm 5.39$ & $7.74 \pm 0.93$ & $4.04 \pm 0.80$ \\
\hline
\end{tabular}

Note: Single plant indicates the A. splendens species. Type A-D mean the grouped vegetation that has been explained in Figure 1. Hp, canopy height; Wp, crown width; P, canopy length; H, snow depth; W, snow width; L, snow braid length; Sp, shrub area; $S$, bottom area of snow; $\mathrm{V}$, snow volume. Mean \pm SE.

\subsection{Snow resisting capacity of shrubs and herbs}

The variation of bottom area of snow affected by shrubs and herbs is a manifestation of snow resisting capacity. Figure 5 showed the relationship between bottom area of snow and windward area $(\mathrm{Hp} \times \mathrm{Wp})$ for $A$. splendens and $C$. microphylla. It can be seen that bottom area of snow had a significant relationship with the windward areas of $C$. microphylla and A. splendens $\left(R^{2}=0.81\right.$ and $\left.R^{2}=0.75\right)$. As the windward area of $C$. microphylla and A. splendens increased, bottom area of snow increased too. The increase in bottom area of snow was rapid for the small windward area of vegetation (0.0-0.8 $\mathrm{m}^{2}$ for C. microphylla and $0.0-0.5 \mathrm{~m}^{2}$ for $A$. splendens). However, with the increase in windward area of vegetation, the increase in bottom area of snow was slow and became gradually stable when the windward area of vegetation was $0.8 \mathrm{~m}^{2}$ for C. microphylla and $0.5 \mathrm{~m}^{2}$ for $A$. splendens.
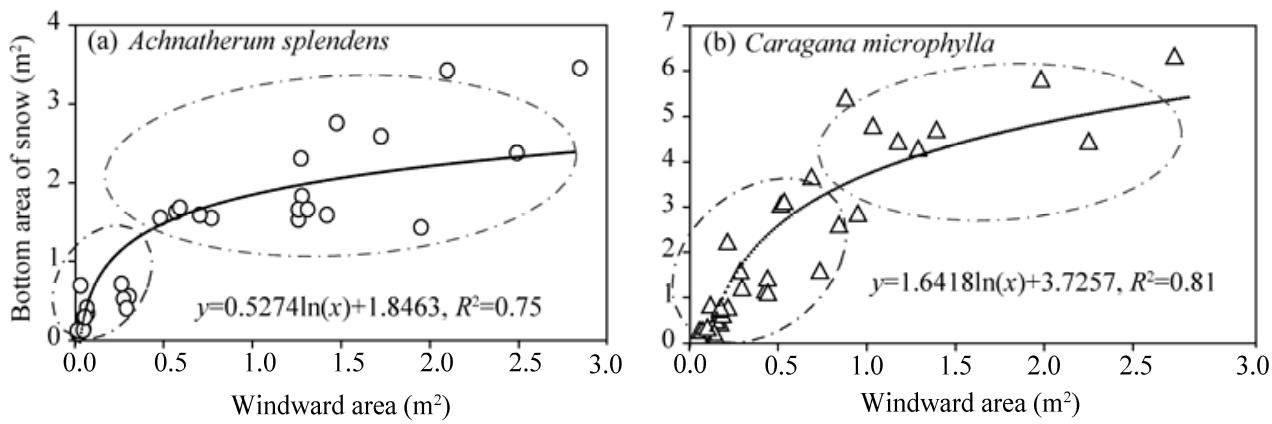

Fig. 5 Relationship between bottom area of snow and windward area ( $\mathrm{Hp} \times \mathrm{Wp})$ of Achnatherum splendens (a) and Caragana microphylla (b). Big oval and small oval mean rapid increase and slow increase in bottom area of snow, respectively. Trend line of bottom area of snow is shown. Hp, canopy height; Wp, crown width.

Figure 6 showed the relationship between the volume of two species $(\mathrm{Hp} \times \mathrm{Wp} \times \mathrm{P})$ and snow volume. It can be seen that snow volume had a significant relationship with the volumes of $C$. microphylla and A. splendens $\left(R^{2}=0.81\right.$ and $\left.R^{2}=0.82\right)$. As vegetation volume increased, snow volume increased too. The increase in snow volume was rapid for the less vegetation volume vegetation $\left(0.0-0.3 \mathrm{~m}^{3}\right.$ for C. microphylla and $0.0-0.6 \mathrm{~m}^{3}$ for A. splendens). However, snow volume tended to become stable with further increases in the volumes of shrub and herb. 

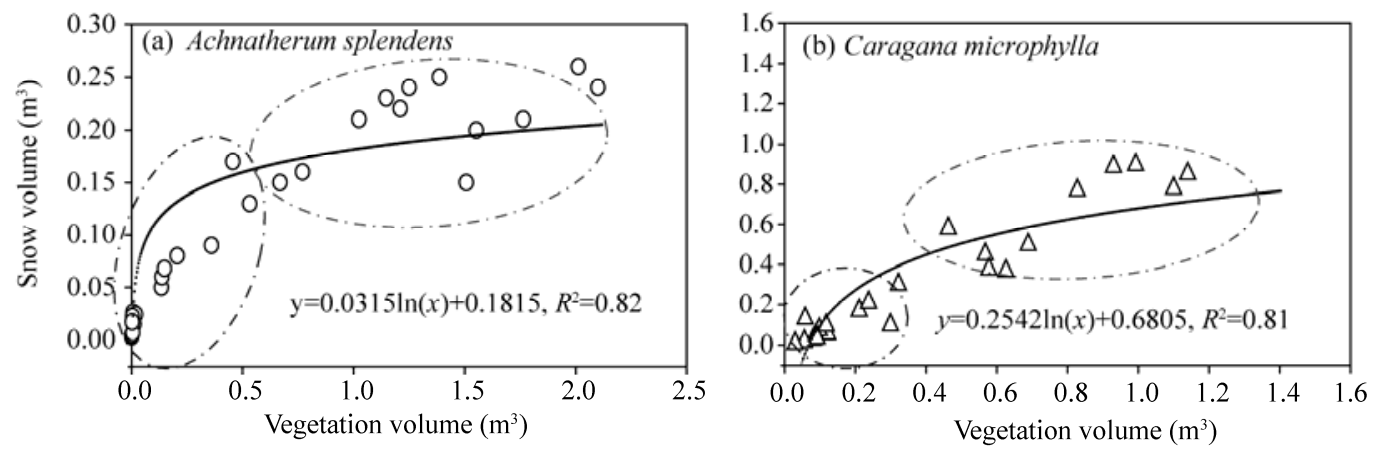

Fig. 6 Relationship between snow volume and vegetation volume of Achnatherum splendens (a) and Caragana microphylla (b). Big oval and small oval mean rapid increase and slow increase in snow volume, respectively.

\section{Discussion}

Existing models of blowing snow and snow cover indicate that snow accumulation is very sensitive to the canopy height and crown width of shrubs, although the size of shrub is an important factor in the snow accumulation process (Sturm et al., 2001; Essery and Pomeroy, 2004). In areas of alpine tundra, the height and canopy breadth of shrubs significantly affect snow depth, and the snow depth in the area with shrub in the Arctic is 4-5 times that of areas with sparse vegetation (Pomeroy et al., 1997). Similar results found that the snow morphological characteristics during accumulation process in cold regions can be significantly altered by variations in height and coverage of shrubs (Menard et al., 2014). In this study, we found that crown width has significant influence on snow morphology $\left(R^{2}>0.75\right)$, while canopy length has little influence. This result can be used to select the plant species with large crown width for improving the capacity of resisting snow damage.

Many field observations have indicated that vegetation coverage determines the amount of snow cover in a region, and similar results regarding snow accumulation have been obtained in grassland. If the baseline of snow water equivalent is taken as the monitored snow water equivalent in a stubble field of the peneplain, the relative snow water equivalent of grazed grassland was 0.60 , ungrazed grassland was 2.85 and shrubland was 4.20 (Gray, 1979). The result implied that the influence of shrub on snow cover was higher than that of grass. Meanwhile, observations have revealed a significant correlation of vegetation parameters of shrubs and herbs with snow depth. It has been found that the amount of snow on shrub is greater than that of on grass. The result of this study showed that there was a significant correlation between vegetation parameters of both $C$. microphylla and $A$. splendens and snow morphology. Crown width of $0.1-1.5 \mathrm{~m}$ for $A$. splendens resulted in snow braid length of $0.3-3.5 \mathrm{~m}$, snow width of $0.1-2.0 \mathrm{~m}$ and snow depth of $0.1-0.5 \mathrm{~m}$. For C. microphylla, crown width of $0.5-4.0 \mathrm{~m}$ resulted in snow braid length of 1.5-7.0 m, snow width of $0.5-3.0 \mathrm{~m}$ and snow depth of $0.1-0.4 \mathrm{~m}$. The area of stagnant snow for a single plant was $1.5-2.5 \mathrm{~m}^{2}$ and the snow volume was $0.15-0.20 \mathrm{~m}^{3}$.

Snow and sand accumulation in association with shrubs and herbs are products of snow drifting and windblown sand transport and accumulation, and snow drifting and windblown sand that both represent dual phase gas-solid flow have similar migration trends. Snow grains are more viscous than sand grains; therefore, it is easier for snow to accumulate on the leeward side of shrubs and herbs (Musick and Gillette, 1996; Yan et al., 2018). In studying the mechanism of prevention of snow movement by shrubs and herbs, lessons can be drawn from studies of the similar mechanism associated with windblown sand and vegetation. When windblown sand approaches an individual shrub or herb specimen, a deceleration zone is formed in front of the shrub or herb and a portion of the sand is deposited. Concurrently, acceleration zones are formed on either side and above the plant. On the leeward side of the plant, the wind speed decreases rapidly because of the eddy effect and a low-speed zone is formed. Beyond a certain distance downwind of the plant, the wind speed gradually recovers in a wake area, causing sand particles to be deposited (Ash and Wasson, 1983; Frank and Kocurek, 1996; Walker and Nickling, 2002). The vegetation 
morphology and wind field characteristics determined the observations and analytical results of this study, verifying the similarity of the mechanism of accumulation of sand and snow in association with shrubs and herbs. Therefore, the bottom area of snow partly and indirectly reflects the snow resisting capacity of the shrubs and herbs, and the snow volume directly reflects the snow amount covered by the shrubs and herbs. Both of them determine the snow resisting capacity of the shrubs and herbs.

This study also confirms the snow resisting capacity under different combinations of vegetation types in the steppe region of Inner Mongolia. When a single plant is in a line perpendicular to the direction of prevailing wind, the blocking range to the wind will be increased and sediment of snowdrift will be deposited on the leeward side. However, when the plant grew in the downwind direction, although the plant coverage might increase, its blocking range is less changed. Thus, any increase in its ability to resist wind and snow accumulate will be minimal. However, when the plant grew in clumps, both the coverage and the density of plant will increase, and its blocking range to wind and its capacity to snow accumulate will significantly increase. Thus, this type of vegetation has the greatest capacity to resist wind and sediment. Similarly to this study, we found that the potential snow area and snow volume retarded in type D were respectively 4 and 25 times that of a single plant, indicating that the clumped distribution of vegetation had the greatest capacity of resisting snow in four types of vegetation.

\section{Conclusions}

We found that canopy height had the greatest influence on snow depth, crown width had the greatest effect on both snow width and snow braid length, while canopy length had little effect on snow morphology. Snow resisting capacity could be significantly changed by different clumped vegetation. Shrubs and herbs having high coverage and canopy height and growing in windward direction were the most snow resistant in the steppe region of Inner Mongolia.

\section{Acknowledgements}

This work was supported by the National Natural Science Foundation of China (41361012), and the Postgraduate Research and Innovation Funding Project of Inner Mongolia Autonomous Region (B2018111951).

\section{References}

Ash J E, Wasson R J. 1983. Vegetation and sand mobility in the Australian desert dunefield. Zeitschift für Geomorphologie Supplementband, 45: 7-25.

Cacitua G, Bay C, Pedersen M R, et al. 2013. Quantifying snow and vegetation interactions in the High Arctic based on ground penetrating radar (GPR). Arctic, Antarctic, and Alpine Research, 45(2): 201-210.

Conner L, Gill R, Harvey J. 2017. Earlier snowmelt accompanied by warmer soil temperatures in mid-latitude aspen forest and subalpine meadow: Implications for soil carbon. Plant and Soil, 417(1-2): 275-285.

Cornelissen J H C, Makoto K. 2014. Winter climate change, plant traits and nutrient and carbon cycling in cold biomes. Ecological Research, 29(4): 517-527.

Dolman A J, Hall A J, Kavvas M L, et al. 2001. Soil-Vegetation-Atmosphere Transfer Schemes and Large-Scale Hydrological Models. Wallingford: IAHS Press, 317-325.

Essery R, Pomeroy J. 2004. Vegetation and topographic control of wind-blown snow distributions in distributed and aggregated simulations for an Arctic tundra basin. Journal of Hydrometeorology, 5(5): 735-744.

Fan L L, Li Y, Tang L S, et al. 2013. Combined effects of snow depth and nitrogen addition on ephemeral growth at the southern edge of the Gurbantunggut Desert, China. Journal of Arid Land, 5(4): 500-510.

Frank A, Kocurek K. 1996. Toward a model for airflow on the lee side of aeolian dunes. Sedimentology, 43(3): 451-458.

Gavazov K, Ingrisch J, Hasibeder R, et al. 2017. Winter ecology of a subalpine grassland: Effects of snow removal on soil respiration, microbial structure and function. Science of the Total Environment, 590-591: 316-324.

Gray D M. 1979. Snow accumulation and redistribution. In: Colbeck S C, Ray M. Proceedings, Modeling of Snow Cover Runoff. Hanover: US Army Cold Regions Research and Engineering Laboratory, 3-33.

Hallinger M, Manthey M, Wilmking M. 2010. Establishing a missing link: warm summers and winter snow cover promote shrub expansion into alpine tundra in Scandinavia. New Phytologist, 186(4): 890-899. 
Hao L, Gao J M, Yang C Y. 2006. Snow disaster system of grassland animal husbandry and control countermeasures. Pratacultural Science, 6: 48-54. (in Chinese)

Johansson M, Callaghan T V, Bosio J, et al. 2013. Rapid responses of permafrost and vegetation to experimentally increased snow cover in sub-arctic Sweden. Environmental Research Letters, 8(3): 035025.

Jones H G, Pomeroy J W, Walker D A, et al. 2001. Snow Ecology: An Interdisciplinary Examination of Snow-covered Ecosystems. Cambridge: Cambridge University Press, 34-48.

Lawrence D M, Oleson K W, Flanner M G, et al. 2011. Parameterization improvements and functional and structural advances in version 4 of the community land model. Journal of Advances in Modeling Earth Systems, 3(1): 1-27.

Leonard K C, Maksym T. 2011. The importance of wind-blown snow redistribution to snow accumulation on Bellingshausen Sea Ice. Annals of Glaciology, 52(57): 271-278.

Liston G E, Hiemstra C A. 2011. Representing grass and shrub snow atmosphere interactions in climate system models. Journal of Climate, 24(8): 2061-2079.

Marion G M, Henry G H R, Freckman D, et al. 1997. Open-top designs for manipulating field temperature in high-latitude ecosystems. Global Change Boil, 3(S1): 30-32.

Marsh P, Bartlett P, MacKay M, et al. 2010. Snowmelt energetics at a shrub tundra site in the western Canadian Arctic. Hydrological Processes, 24(25): 3603-3620.

Ménard C B, Essery R, Pomeroy J, et al. 2014. A shrub bending model to calculate the albedo of shrub-tundra. Hydrological Processes, 28(2): 341-351.

Musick H B, Gillette D A. 1990. Field evaluation of relationships between a vegetation structural parameter and sheltering against wind erosion. Land Degradation and Development, 2(2): 87-94.

Myers-Smith I H. 2011. Shrub encroachment in Arctic and alpine tundra: mechanisms of expansion and ecosystem impacts. PhD Dissertation. Edmonton: University of Alberta, 7-19.

Naito A T, Cairns D M. 2011. Patterns and processes of global shrub expansion. Progress in Physical Geography, 35(4): 423-442.

Pomeroy J W, Marsh P, Gray D M. 1997. Application of a distributed blowing snow model to the Arctic. Hydrological Processes, 11(11): 1454-1464.

Pomeroy J W, Bewley D S, Essery R, et al. 2006. Shrub tundra snowmelt. Hydrological Processes, 20(4): $923-941$.

Schmidt N M, Baittinger C, Kollmann J, et al. 2010. Consistent dendrochronological response of the dioecious Salix arctica to variation in local snow precipitation across gender and vegetation types. Arctic Antarctic and Alpine Research, 42(4): $471-475$.

Sturm M, McFadden J P, Liston G E, et al. 2001. Snow-shrub interactions in Arctic tundra: A hypothesis with climatic implications. Journal of Climate, 14(3): 336-344.

Sturm M, Douglas T, Racine C, et al. 2005. Changing snow and shrub conditions affect albedo with global implications. Journal of Geophysical Research: Biogeosciences, 110(G1): 1-13.

Tinkham W T, Smith A, Marshall H P, et al. 2014. Quantifying spatial distribution of snow depth errors from LiDAR using random forest. Remote Sensing of Environment, 141: 105-115.

Tommaso C, Sprugnoli R, Manuela S, et al. 2014. Evaluation of events and temporal information at Evalita. In: Proceedings of the First Italian Conference on Computational Linguistics CLiC-it 2014 \& the Fourth International Workshop. Evalita: Pisa University Press, 27-34.

Walker I J, Nickling W C. 2002. Dynamics of secondary airflow and sediment transport over and in the lee of transverse dunes. Progress in Physical Geography, 26(1): 47-75.

Walker K D, Ingersoll R C, Webber P J. 1995. Effects of interannual climate variation on phenology and growth of two alpine forbs. Ecology, 76(4): 1067-1083.

Wipf S, Rixen C. 2010. A review of snow manipulation experiments in Arctic and alpine tundra ecosystems. Polar Research, 29(1): 95-109.

Yan M, Zuo H J, Dong Z, et al. 2018. Capacity of Caragana microphylla shrub on counteracting snow movement and its influence on snow morphology in the Xilinhot Steppe, China. Chinese Journal of Applied Ecology, 29(2): 483-491. (in Chinese) 